\title{
Study on Transverse Displacement in Composite Laminated Plates across Thickness Subjected to Various Thermal Profiles
}

\author{
Kanase A K ${ }^{1}$, Shiyekar S M ${ }^{2}$, Shiyekar M R ${ }^{3}$ \\ ${ }^{1}$ Civil Engineering Department, SITS, Narhe, Pune, India \\ ${ }^{2}$ Civil Engineering Department, SGI, Kolhapur, India \\ ${ }^{3}$ Ex. Professor Walchand Engineering College, Sangli, India
}

\begin{abstract}
In this paper main focus is given on alternative ways of thermal load applied through the thickness of laminated composite plate. Research has assumed gradient or constant thermal profile along the thickness of the plate. Laminated composite is a complex material therefore assumed loading profiles may not obey the gradient or constant thermal profile path therefore, as a research in all total 10 thermal profiles are studied. The results in tabular and graphical forms are presented along with discussion. First Order Shear Deformation Theory (FOST) is used for analysis. Various quantities, namely in plane as well as transverse displacements and stresses are obtained when thermal load is applied in various orientations along the thickness of the plate. Main focus in this article is analysis of transverse shear displacement and results are presented in tabular and graphical form.
\end{abstract}

Keywords: Composite, Transverse, Shear, Deformation, Thermal

\section{Introduction}

Composites are a combination of two or more materials to form a new material that contains the best features of each constituent, so as to optimize certain parameters like strength, stiffness, toughness, fatigue, corrosion resistance, temperature dependent behavior, Thermal insulation, Thermal conductivity, acoustical insulation, etc. Due to their light weight and ease of fabrication, glass and carbon fiber composites are extensively used in plates and shells encountered in aerospace application. Fiber composites are also used in buildings, bridges, aircraft wings, rocket staging, fuselages, hull of ships, automobile bodies, etc.

This paper presents the study of investigation of new thermal profiles along the thickness of simply supported laminated composite plates. The deflections and stresses in the composite laminated plate under Thermal loading using First Order Shear Deformation Theory (FOST) for ten thermal profiles along thickness are evaluated analytically. In this paper main focus is given on analysis of transverse shear displacement for ten thermal profiles because this parameter is highly responsible for delimitation of laminated composite plates in case of thermal loads.

\section{First Order Shear Deformation Theory (FOST)}

Although different single layer, high order theories has been developed to improve stress distributions due to thermal loads, it remains the fact that none of the theories can give good inter laminar stresses. Further, they cannot be used to model delimitations in composite laminates. It is observed that each theory is having its limitations and constraints, but among the Shear Deformation Plate Theories, the First Order Theory seems to provide the best compromise between accuracy and computational efficiency.

Earlier research based on First Order Shear Deformation Theory (FOST) considered in Reissner ${ }^{[1]}$ and Mindlin ${ }^{[2]}$ for solutions to include the thermal effects on laminates. About four decades ago Pagano ${ }^{[3]}$ forecasted Exact solution for composite laminated in cylindrical bending and given basic results in material science which are very helpful for today's research. Kant and Khare ${ }^{[4]}$ developed a simple $\mathrm{C}^{\mathrm{o}}$ iso-parametric Finite Element (FE) displacement model based on HOST formulations for the analysis of symmetric and asymmetric laminates subjected to thermal gradient. Tungikar and $\mathrm{Ra}^{[5]}$ obtained 3D elasticity solution for temperature distribution and thermal stresses in simply supported rectangular laminates. The actual temperature distribution across the thickness of the laminate is evaluated by solving the Ordinary Differential Equations (ODEs) of heat conduction without internal heat generation. The actual profile also satisfies the interface heat flux continuity. Bhaskar et al ${ }^{[6]}$ developed 3D elasticity solution for laminates under cylindrical and bi-directional bending by assuming linear variation of thermal profile through the thickness of the symmetric laminate. Rower et al. ${ }^{[7]}$ removed deficiencies in the FOST by incorporating third and fifth order displacement approximations through the plate thickness. 3D elasticity solution can estimate the correct results of the thermally induced quantities like displacements and stresses. Kant and Swaminathan ${ }^{[8]}$ presented simplified formulations through the paper Analytical solutions for static analysis of laminated composite and sandwich plates based on a higher order refined theory and suggested First Order Shear Deformation Theory as a special case with its importance. 
Matsunaga ${ }^{[9]}$ computed inter laminar stresses as well as displacements in laminated composites. Kapuria et al ${ }^{[10]}$ assessed Higher Order Zig-Zag (HZIGT) model along with exact, Zig-Zag (ZIGT) and Third Order Theory (TOT) models for composite laminates subjected various thermal profiles across the thickness. Kant et $\mathrm{al}^{[11]}$ developed semi-analytical solution for constant and linear temperature variation through the thickness of a laminate for composites and sandwiches. Matsunaga ${ }^{[12]}$ obtained a Two-Dimensional (2D) Higher Order Deformation Theory for the evaluation of displacements and stresses in functionally graded (FG) plates subjected to thermal and mechanical loadings. Kant and Shiyekar ${ }^{[13]}$ developed higher order theory for composite laminates subjected to thermal gradient using (HOSNT12) model.

\section{First Order Shear Deformation Formulation}

Analytical formulation is presented using First Order Shear Deformation Theory (FOST) for a laminate simply supported on all the sides. Effect of transverse shear is neglected considering aim to propose different thermal loads. Fig. 1 represents the geometry of the general laminated composite plate.

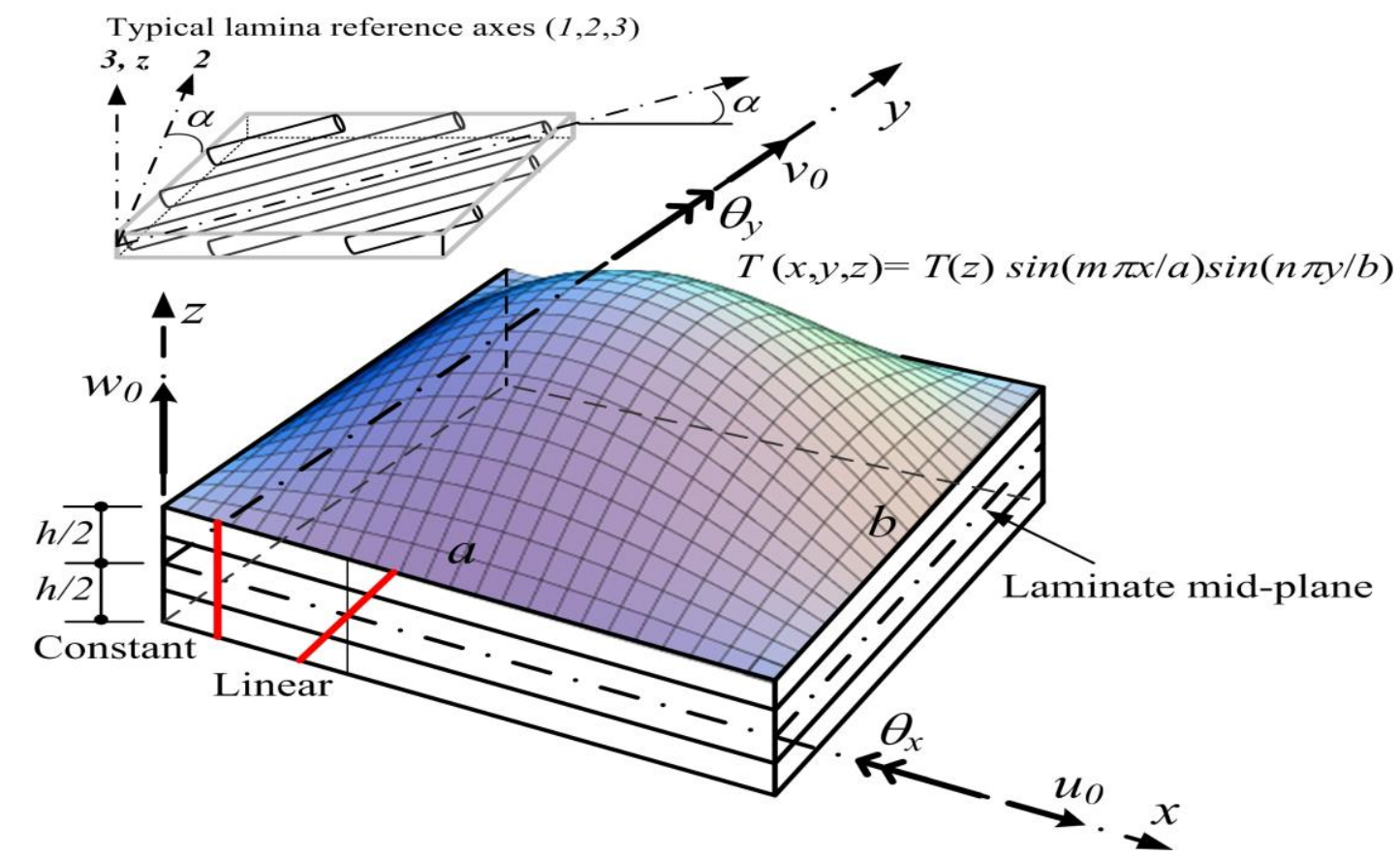

Fig. 1 Laminate geometry (diaphragm) with positive set of laminate reference axes, positive displacement components, fiber orientation and thermal loading across the thickness of the lamina.

The geometry of the laminate is such that the sides ' $a$ ' is along ' $x$ ' axis, ' $b$ ' is on ' $y$ ' axis and thickness of the laminate is denoted by ' $h$ ' is coinciding with ' $z$ ' axis. The reference mid-plane of the laminate is at $h / 2$ from top or bottom surface of the laminate. The lamina reference axes system is also in the figure with fiber direction. The formulation is assuming fiber direction of the single layered lamina is coinciding with ' $x$ ' axis of the laminate. This figure also explains positive set of displacements along $(x-y-z)$ axes, sample thermal profile orientation through the thickness for constant and linear thermal profile. Table 1 explores the mathematical representation of all 10 thermal profiles through the thickness of laminated composite plates. The graphical representation of these profiles is shown in Fig. 2. All thermal profiles are functions of $(x, y, z)$. Variation in $\mathrm{x}$ and y is sinusoidal whereas $T(z)$ is thermal profile, which is a function of $z$ coordinate. Extremities of thermal loading having maximum and minimum amplitude are expressed in terms of $z / h$ ratio in between -0.5 to +0.5 . In all totals there are 4 sets of thermal load applied having different amplitudes in each set of loading. First set contains 3 profiles, namely thermal profile 1,2 and 3 having abbreviations $\mathrm{TP}_{1}, \mathrm{TP}_{2}$ and $\mathrm{TP}_{3}$ respectively. Thermal profile 1, is linear may be called as gradient along the thickness in $z$ direction which is straight through the thickness of the plate. Thermal profiles 2 and 3 are cubic parabola and sinusoidal. Set 2 is having total 3 profiles, namely $\mathrm{TP}_{4}$ (Gradient linear), $\mathrm{TP}_{5}$ (Parabolic degree 3) and $\mathrm{TP}_{6}$ (Parabolic degree 2). Set 3 having 3, thermal profiles $\mathrm{TP}_{7}, \mathrm{TP}_{8}, \mathrm{TP}_{9}$ and Set 4 having only single profile $\mathrm{TP}_{10}$. 
Study on Transverse Displacement in Composite Laminated Plates across Thickness Subjected ....

Table 1 Proposed Thermal Profiles along the thickness of plates.

\begin{tabular}{|c|c|c|}
\hline $\begin{array}{l}\text { Thermal } \\
\text { Profile }\end{array}$ & Equation of Thermal Profile & $(a / 2, b / 2, z)$ \\
\hline $\mathrm{TP}_{1}$ & $T=\frac{2 z}{h} T_{0} \sin (\pi x / a) \sin (\pi y / b)$ (Gradient linear $)$ & \multirow{3}{*}{$\begin{array}{l}-T_{0} \leq T \leq T_{0} \\
T_{0}=\text { Amplitude of Thermal load. } \\
T=\text { Temperature difference. }\end{array}$} \\
\hline $\mathrm{TP}_{2}$ & $T=(2 z / h)^{3} T_{0} \sin (\pi x / a) \sin (\pi y / b)($ Parabolic degree 3$)$ & \\
\hline $\mathrm{TP}_{3}$ & $T=\sin (\pi z / h) T_{0} \sin (\pi x / a) \sin (\pi y / b)$ (Sinusoidal) & \\
\hline $\mathrm{TP}_{4}$ & $T=\left(\frac{z}{h}+\frac{1}{2}\right) T_{0} \sin (\pi x / a) \sin (\pi y / b)($ Gradient linear $)$ & \multirow[t]{3}{*}{$0 \leq T \leq T_{0}$} \\
\hline $\mathrm{TP}_{5}$ & $T=\left(\frac{z}{h}+\frac{1}{2}\right)^{3} T_{0} \sin (\pi x / a) \sin (\pi y / b)($ Parabolic degree 3$)$ & \\
\hline $\mathrm{TP}_{6}$ & $T=\left(\frac{z}{h}+\frac{1}{2}\right)^{2} T_{0} \sin (\pi x / a) \sin (\pi y / b)$ (Parabolic degree 2) & \\
\hline $\mathrm{TP}_{7}$ & $T=T_{0} \sin (\pi x / a) \sin (\pi y / b) \quad$ (Constant) & Constant \\
\hline $\mathrm{TP}_{8}$ & $T=(2 z / h)^{2} T_{0} \sin (\pi x / a) \sin (\pi y / b)($ Parabolic degree 2$)$ & \multirow[t]{2}{*}{0 at center to $T_{0}$ at top and bottom } \\
\hline $\mathrm{TP}_{9}$ & $T=2 a b s(z / h) T_{0} \sin (\pi x / a) \sin (\pi y / b)$ ( Absolute ) & \\
\hline $\mathrm{TP}_{10}$ & $T=\left(1-(2 z / h)^{2}\right) T_{0} \sin (\pi x / a) \sin (\pi y / b)($ Parabolic degree 2$)$ & $\begin{array}{l}T_{0} \text { at center to } 0 \text { at at top and } \\
\text { bottom }\end{array}$ \\
\hline
\end{tabular}

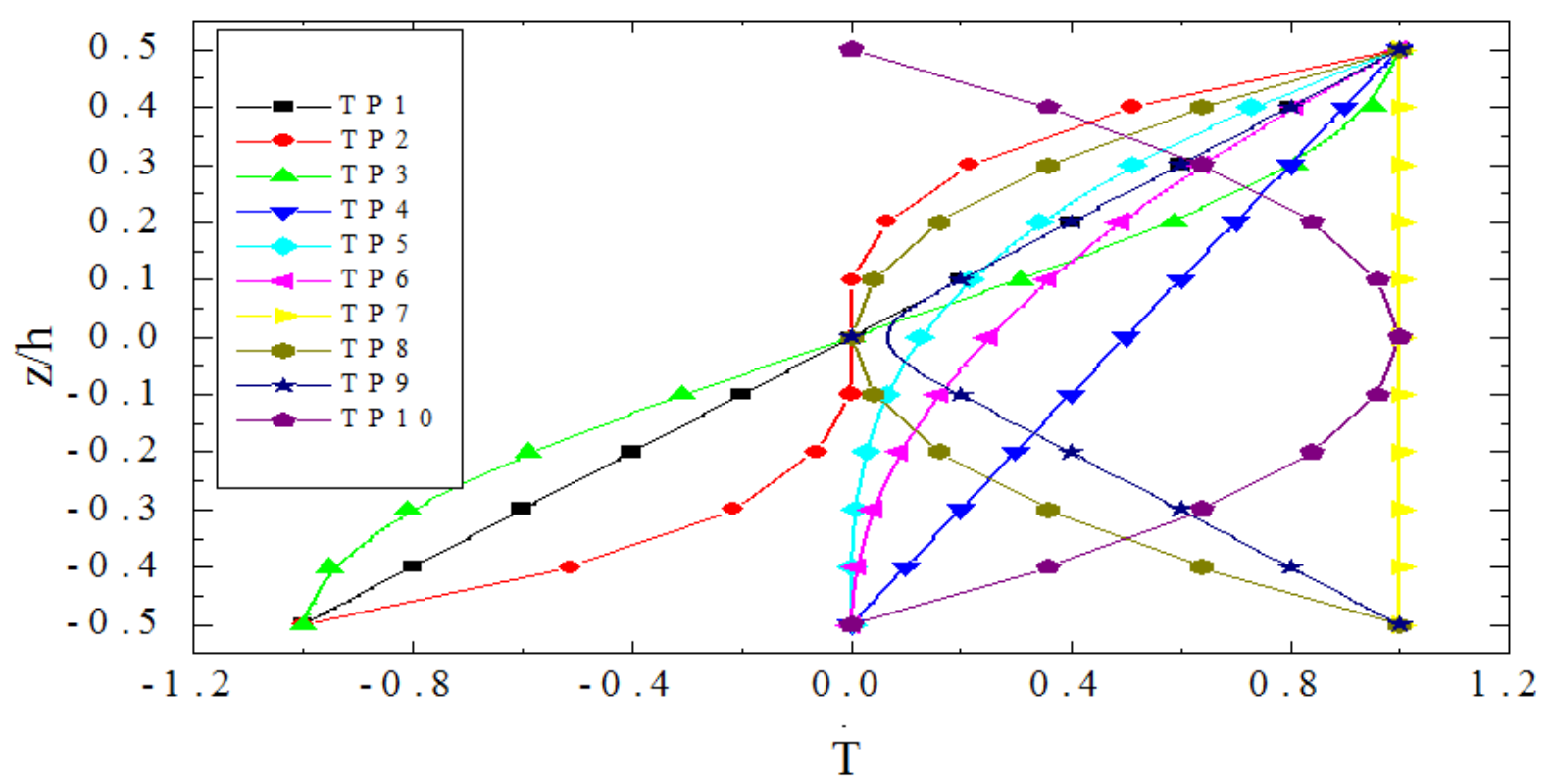

Fig. 2 Thermal loading variations of Thermal Profiles 1 to 10 across the thickness of the laminate

\subsection{Displacement field}

Displacement field used in FOST (First Order Shear Deformation Theory) for calculating displacements and stresses is by the analytical method and given bellow:

$u(x, y, z)=u_{0}(x, y)+z \theta_{x}(x, y), v(x, y, z)=v_{0}(x, y)+z \theta_{y}(x, y), w(x, y)=w_{0}(x, y)$

Here $(u, v, w)$ denote the displacements of a point in the $(x, y, z)$ coordinate directions at any point due to applied load. Functions $\theta_{x}$ and $\theta_{y}$ are rotation of the normal to the middle plane about $y$ - axis and $x$ - axis respectively. Mid plane displacements are $\left(u_{0}, v_{0}, w_{0}\right)$ on a plate in the $(x, y)$ coordinate directions. 


\subsection{Strain-displacement relations from displacement field}

Linear theory of elasticity gives the general strain-displacement relationships for very small displacements given as below:

$$
\left\{\begin{array}{l}
\varepsilon_{x} \\
\varepsilon_{y} \\
\gamma_{x y} \\
\gamma_{x z} \\
\gamma_{y z}
\end{array}\right\}=\left\{\frac{\partial u}{\partial x}, \frac{\partial v}{\partial y}, \frac{\partial u}{\partial y}+\frac{\partial v}{\partial x}, \quad \frac{\partial u}{\partial z}+\frac{\partial w}{\partial x}, \frac{\partial v}{\partial z}+\frac{\partial w}{\partial y} \cdot\right\}^{t}
$$

Where $\varepsilon_{x}, \varepsilon_{y}$ are normal strains with respect to plate axes $\mathrm{x}, \mathrm{y} . \gamma_{x y}$ is in plane shear strain in $\mathrm{x}-\mathrm{y}$ plane. $\gamma_{x z}, \gamma_{y z}$ transverse shear strains in $x z$ and $y z$ planes respectively, as well as three dimensional problems reduced to two dimensional by considering $\varepsilon_{z}=\frac{\partial w}{\partial x}=0$ as displacement in $z$ direction assumed to be constant.

\subsection{Stress - Strain relations}

Each lamina in the laminate is assumed to be in a three dimensional stress state so that the constitutive relation for a typical lamina $\mathrm{L}$ with reference to the fiber-matrix coordinate axes (1-2-3) can be written as

$$
\left\{\begin{array}{l}
\sigma_{1} \\
\sigma_{2} \\
\tau_{12} \\
\tau_{13} \\
\tau_{23}
\end{array}\right\}=\left[\begin{array}{ccccc}
C_{11} & C_{12} & 0 & 0 & 0 \\
C_{12} & C_{22} & 0 & 0 & 0 \\
0 & 0 & C_{33} & 0 & 0 \\
0 & 0 & 0 & C_{44} & 0 \\
0 & 0 & 0 & 0 & C_{55}
\end{array}\right]^{L} \cdot\left\{\begin{array}{c}
\varepsilon_{1}-\alpha_{1} T \\
\varepsilon_{2}-\alpha_{1} T \\
\gamma_{12} \\
\gamma_{13} \\
\gamma_{23}
\end{array}\right\}
$$

Where $\left(\sigma_{1}, \sigma_{2}, \tau_{12}, \tau_{13}, \tau_{23}\right)$ are the stresses and $\left(\varepsilon_{1}, \varepsilon_{2}, \gamma_{12}, \gamma_{13}, \gamma_{23}\right)$ are the linear strain components referred to the lamina coordinates (1-2-3) and $C_{i j}$ are the elements of stiffness matrix of the Lth lamina with reference to the fiber axes (1-2-3).

In the laminate coordinates $(x, y, z)$ the stress strain relations for the $\mathrm{L}^{\text {th }}$ lamina can be written as

$$
\left\{\begin{array}{l}
\sigma_{x} \\
\sigma_{y} \\
\tau_{x y} \\
\tau_{x z} \\
\tau_{y z}
\end{array}\right\}=\left[\begin{array}{ccccc}
Q_{11} & Q_{12} & 0 & 0 & 0 \\
Q_{12} & Q_{22} & 0 & 0 & 0 \\
0 & 0 & Q_{33} & 0 & 0 \\
0 & 0 & 0 & Q_{44} & 0 \\
0 & 0 & 0 & 0 & Q_{55}
\end{array}\right]^{L} \cdot\left\{\begin{array}{c}
\varepsilon_{x}-\alpha_{x} T \\
\varepsilon_{y}-\alpha_{y} T \\
\gamma_{x y} \\
\gamma_{x z} \\
\gamma_{y z}
\end{array}\right\}
$$

Where $\left(\sigma_{x}, \sigma_{y}, \tau_{x y}\right)$ are the stresses and $\left(\varepsilon_{x}, \varepsilon_{y}, \gamma_{x y}, \gamma_{x z}, \gamma_{y z}\right)$ are the strains with respect to the laminate axes. $Q_{i j}$ are the transformed elastic constants or elements of stiffness matrix with respect to the laminate axes $\mathrm{x}, \mathrm{y}, \mathrm{z}$. The elements of matrices [ $\left.C_{i j}\right]$ and [ $\left.Q_{i j}\right]$ are defined in Appendix A. In Eq. (3), the compliance matrix involves engineering properties, namely two Young's moduli $\left(E_{1}, E_{2}\right)$, two Poisson's ratios $\left(v_{12}, v_{21}\right)$ and three shear moduli $\left(G_{12}, G_{13}, G_{23}\right)$.

The relation between Elastic moduli and Poisson's ratios is given as, $\frac{v_{21}}{E_{2}}=\frac{v_{12}}{E_{1}}$.

Where $\alpha_{1}, \alpha_{2}$ are the linear thermal expansions coefficients with respect to lamina reference axes and $\alpha_{x}, \alpha_{y}$ are the linear thermal expansion coefficients with respect to laminate reference axes. $T$ is the difference in temperature between two faces of the plate. The relations given by Eq. (4) are adopted to develop a theoretical formulation based on the displacement model FOST. 


\subsection{Stress resultants}

The state of stress in a plate will be two-dimensional. In Cartesian coordinates, the state of stress may be identified as normal stresses and shear stresses. Since these moments are resultant of the stresses developed on the plate, these are called stress resultants and forces per unit length of the plate.

\subsubsection{Elastic stress resultants at $L^{\text {th }}$ layer in analytical solution}

$$
\begin{aligned}
& M_{x}{ }^{E}=\sum_{L=1}^{N L} \int_{Z_{L}}^{Z_{L+1}}\left(\sigma_{x} z\right) d z, M_{y}{ }^{E}=\sum_{L=1}^{N L} \int_{Z_{L}}^{Z_{L+1}}\left(\sigma_{y} z\right) d z, \\
& M_{x y}{ }^{E}=\sum_{L=1}^{N L} \int_{Z_{L}}^{Z_{L+1}}\left(\tau_{x y} z\right) d z, Q_{x}{ }^{E}=\sum_{L=1}^{N L} \int_{Z_{L}}^{Z_{L+1}}\left(\tau_{x z}\right) d z, \\
& Q_{y}{ }^{E}=\sum_{L=1}^{N L} \int_{Z_{L}}^{Z_{L+1}} \tau_{y z} d z, N_{x}{ }^{E}=\sum_{L=1}^{N L} \int_{Z_{L}}^{Z_{L+1}}\left(\sigma_{x}\right) d z, \\
& N_{y}{ }^{E}=\sum_{L=1}^{N L} \int_{Z_{L}}^{Z_{L+1}}\left(\sigma_{y}\right) d z, N_{x y}{ }^{E}=\sum_{L=1}^{N L} \int_{Z_{L}}^{Z_{L+1}}\left(\tau_{x y}\right) d z,
\end{aligned}
$$

\subsubsection{Thermal stress resultants at $\mathrm{L}^{\text {th }}$ layer in analytical solution}

$$
\begin{aligned}
& M_{x}{ }^{T}=\sum_{L=1}^{N L} \int_{Z_{L}}^{Z_{L+1}}\left(Q_{11} \alpha_{x} T+Q_{12} \alpha_{y} T\right) z d z, M_{y}{ }^{T}=\sum_{L=1}^{N L} \int_{Z_{L}}^{Z_{L+1}}\left(Q_{12} \alpha_{x} T+Q_{22} \alpha_{y} T\right) z d z, \\
& N_{x}{ }^{T}=\sum_{L=1}^{N L} \int_{Z_{L}}^{Z_{L+1}}\left(Q_{11} \alpha_{x} T+Q_{12} \alpha_{y} T\right) d z, N_{y}{ }^{T}=\sum_{L=1}^{N L} \int_{Z_{L}}^{Z_{L+1}}\left(Q_{12} \alpha_{x} T+Q_{22} \alpha_{y} T\right) d z, \\
& Q_{x}{ }^{T}=Q_{y}{ }^{T}=M_{x y}{ }^{T}=N_{x y}{ }^{T}=0 .
\end{aligned}
$$

\subsubsection{Final stress resultants at $\mathrm{L}^{\text {th }}$ layer in analytical solution}

$$
\begin{aligned}
& \left\{N_{x} N_{y} N_{x y} M_{x} M_{y} M_{x y} Q_{x} Q_{y}\right\}= \\
& \left\{N_{x} N_{y} N_{x y} M_{x} M_{y} M_{x y} Q_{x} Q_{y}{ }^{\mathrm{E}}-\left\{N_{x} N_{y} N_{x y} M_{x} M_{y} M_{x y} Q_{x} Q_{y}\right\}^{\mathrm{T}}\right.
\end{aligned}
$$

\subsection{Governing equations of equilibrium and boundary conditions}

For obtaining governing equations use the principle work, following equations of equilibrium are obtained with appropriate boundary conditions

$$
\delta(U+V)=0 \text {, }
$$

Here, $\mathrm{U}=$ total strain energy due to deformation, the $\mathrm{V}=$ potential of the external loads, $\mathrm{U}+\mathrm{V}=\Pi$ which is the total potential energy. $\delta$ = variational symbol. Putting the energy expressed in the above equation, the final expression is written as

$$
\delta \Pi=\left[\int_{-h / 2}^{+h / 2} \int_{A}\left(\sigma_{x} \delta \varepsilon_{x}+\sigma_{y} \delta \varepsilon_{y}+\tau_{x y} \delta \gamma_{x y}+\tau_{y z} \delta \gamma_{y z}+\tau_{x z} \delta \gamma_{x z}\right) d A d z-\int_{A} q_{z}^{+} \delta w^{+} d A\right]=0
$$

We get the following equations of equilibrium, 


$$
\begin{aligned}
& \delta u_{0}: \frac{\partial N_{x}}{\partial x}+\frac{\partial N_{x y}}{\partial y}=0 \\
& \delta v_{0}: \frac{\partial N_{y}}{\partial y}+\frac{\partial N_{x y}}{\partial x}=0 \\
& \delta w_{0}: \frac{\partial Q_{x}}{\partial x}+\frac{\partial Q_{y}}{\partial y}+\left(q_{z}^{+}\right)=0 \\
& \delta \theta_{x}: \frac{\partial M_{x}}{\partial x}+\frac{\partial M_{x y}}{\partial y}-Q_{x}=0 \\
& \delta \theta_{y}: \frac{\partial M_{y}}{\partial y}+\frac{\partial M_{x y}}{\partial x}-Q_{y}=0
\end{aligned}
$$

Following are the boundary conditions used for simply supported plate Subjected to mechanical and thermal load.

At edge $\mathrm{x}=0$ and $\mathrm{x}=\mathrm{a}$ :

$\mathrm{v}_{0}=0, \mathrm{w}_{0}=0, \theta_{\mathrm{y}}=0, \mathrm{M}_{\mathrm{x}}=0, \mathrm{~N}_{\mathrm{x}}=0$.

At edges $\mathrm{y}=0$ and $\mathrm{y}=\mathrm{b}$ :

$\mathrm{u}_{0}=0, \mathrm{w}_{0}=0, \theta_{\mathrm{x}}=0, \mathrm{M}_{\mathrm{y}}=0, \mathrm{~N}_{\mathrm{y}}=0$.

Navier's solution procedure is adopted to find the solution to displacement variables, satisfying the above boundary conditions is expressed as per the following

$$
\begin{aligned}
& u_{0}=\sum_{m=1,3,5}^{\infty} \sum_{n=1,3,5}^{\infty} u_{0_{m n}} \cos \left(\alpha_{m} x\right) \sin \left(\beta_{n} y\right), \\
& v_{0}=\sum_{m=1,3,5}^{\infty} \sum_{n=1,3,5}^{\infty} v_{0_{m n}} \sin \left(\alpha_{m} x\right) \cos \left(\beta_{n} y\right), \\
& w_{0}=\sum_{m=1,3,5}^{\infty} \sum_{n=1,3,5}^{\infty} w_{0_{m n}} \sin \left(\alpha_{m} x\right) \sin \left(\beta_{n} y\right), \\
& \theta_{x}=\sum_{m=1,3,5}^{\infty} \sum_{n=1,3,5}^{\infty} \theta_{x_{m n}} \cos \left(\alpha_{m} x\right) \sin \left(\beta_{n} y\right), \\
& \theta_{y}=\sum_{m=1,3,5}^{\infty} \sum_{n=1,3,5}^{\infty} \theta_{y_{m n}} \sin \left(\alpha_{m} x\right) \cos \left(\beta_{n} y\right) .
\end{aligned}
$$

The thermal load is expressed as doubly sinusoidal loading on top of the laminate as.

$$
T=\sum_{m=1}^{\infty} \sum_{n=1}^{\infty} T(z)_{m n} \sin \left(\alpha_{m} x\right) \sin \left(\beta_{n} y\right)
$$

Where $T(z)$ is a Thermal Profile over the thickness of the laminate

Where $\alpha_{m}=\frac{m \pi}{a}, \beta_{n}=\frac{n \pi}{b} \ldots \ldots . m=1,3,5 \ldots$ and $n=1,3,5 \ldots$ etc.

Considering single harmony $m=1, n=1$ and substituting equation 7 into equation 10 and collecting the coefficients once obtains,

$[\mathrm{X}] .[\delta]=[\mathrm{q}] .\left[T_{F}\right] \ldots$

Where $[X]=$ Stiffness matrix of order $5 \times 5,\{\delta\}=$ Amplitudes of displacements of order $5 \times 1$, $\{q\}=$ Mechanical load vector of order $5 \times 1$ and $\left\{T_{F}\right\}=$ Thermal load vector of order $5 \times 1$ respectively given as,

The elements of the coefficient matrix and Thermal load coefficient matrix $\left\{T_{F}\right\}$ are calculated using computer programming. 


$$
[X]=\left[\begin{array}{lllll}
X_{1,1} & X_{1,2} & X_{1,3} & X_{1,4} & X_{1,5} \\
X_{2,1} & X_{2,2} & X_{2,3} & X_{2,4} & X_{2,5} \\
X_{3,1} & X_{3,2} & X_{3,3} & X_{3,4} & X_{3,5} \\
X_{4,1} & X_{4,2} & X_{4,3} & X_{4,4} & X_{4,5} \\
X_{5,1} & X_{5,2} & X_{5,3} & X_{5,4} & X_{5,5}
\end{array}\right]^{L},\{\delta\}=\left\{\begin{array}{c}
u_{0_{m n}} \\
v_{0_{m n}} \\
w_{0_{m n}} \\
\theta_{x_{m n}} \\
\theta_{y_{m n}}
\end{array}\right\}^{L},\{q\}=\left\{\begin{array}{c}
0 \\
0 \\
q_{z}^{+} \\
0 \\
0
\end{array}\right\}^{L},\{T\}=\left\{\begin{array}{l}
T_{F_{1,1}} \\
T_{F_{2,1}} \\
T_{F_{3,1}} \\
T_{F_{4,1}} \\
T_{F_{5,1}}
\end{array}\right\}^{L}
$$

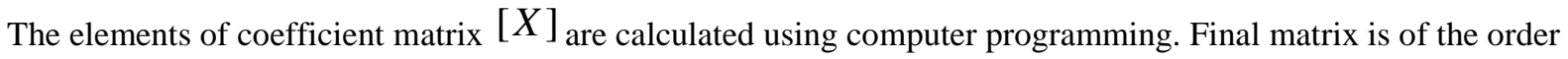
$5 \times 1$. Here only thermal load is applied for 10 Thermal Profiles and coefficient matrix $\{T\}$ are calculated using computer programming. For this formulation mechanical load $q_{z}^{+}=0$.

\section{Discussion}

Following configurations of the laminates are analyzed and discussed

Ex.1-Isotropic square plate,

Ex.2-Single layer orthotropic square plate $\left(0^{0}\right)$,

Ex.3-Unsymmetrical laminated square plate $\left(0^{\circ} / 90^{\circ}\right)$,

Ex.4-Symmetric laminated square plate $\left(0^{0} / 90^{\circ} / 0^{\circ}\right)$,

Ex.5-Symmetric laminated square plate $\left(0^{\circ} / 90^{\circ} / 90^{\circ} / 0^{\circ}\right)$,

Ex.6-Symmetric laminated rectangular plate $\left(0^{\circ} / 90^{\circ} / 90^{\circ} / 0^{\circ}\right)$,

Ex.7-Unsymmetrical laminated square plate $\left(90^{\circ} / 0^{\circ} / 90^{\circ} / 0^{\circ}\right)$.

The material properties along with individual lamina and normalization coefficients are tabulated in Table 2.

\section{Example 1}

A simply supported square isotropic plate is analyzed for 10 different thermal loading profiles as mentioned in Table 1. Analysis is done for transverse transverse displacement $(\bar{w})$ and results are compared with Mastunaga ${ }^{[12]}$

Table 2 Elastic and thermal material properties

\begin{tabular}{|c|c|c|}
\hline $\begin{array}{l}\text { Example } \\
\text { and } \\
\text { Reference }\end{array}$ & Properties & Normalization \\
\hline $1[12]$ & $\begin{aligned} \text { Ceramic }\left(\text { Alumina } \mathrm{Al}_{2} \mathrm{O}_{3}\right), \mathrm{GPa}=10^{9}, \\
\mathrm{E}_{1}=\mathrm{E}_{2}=\mathrm{E}_{\mathrm{c}}=380 \mathrm{Gpa} . \\
v_{12}=v_{\mathrm{c}}=0.3 \\
\alpha_{1}=7.4 \times 10^{-6} \mathrm{~K}^{-1} .\end{aligned}$ & $(\bar{u}, \bar{v}, \bar{w})=\frac{(u, v, w)}{\alpha_{c} T_{0} h},\left(\bar{\sigma}_{i}, \bar{\tau}_{i j}\right)=\frac{\left(\sigma_{i}, \tau_{i j}\right)}{\alpha_{c} T_{0} E c}$ \\
\hline $2[11]$ & $\begin{array}{l}\mathrm{E}_{1}=150 \mathrm{GPa}, \mathrm{E}_{2}=10 \mathrm{GPa}, \\
\mathrm{G}_{12}=5 \mathrm{GPa}, \mathrm{G}_{13}=5 \mathrm{GPa}, \mathrm{G}_{23}=3.378 \mathrm{GPa}, \\
v_{12}=v_{13}=v_{23}=0.3, \\
\alpha_{1}=0.139 \times 10^{-6} \mathrm{~K}^{-1} \\
\quad \alpha_{2}=9 \times 10^{-6} \mathrm{~K}^{-1} .\end{array}$ & $\begin{array}{l}S=a / h, \bar{w}=\frac{h^{3} w}{\alpha_{1} T_{0} a^{4}} \\
(\bar{u} ; \bar{v})=\frac{1}{h \alpha_{1} T_{0} S^{3}}(u ; v) \\
\left(\bar{\sigma}_{x} ; \bar{\sigma}_{y} ; \bar{\tau}_{x y}\right)=\frac{1}{E_{2} \alpha_{1} T_{0} S^{2}}\left(\sigma_{x}, \sigma_{x}, \tau_{x y}\right) \\
\left(\bar{\tau}_{x z}, \bar{\tau}_{y z}\right)=\frac{1}{E_{2} \alpha_{1} T_{0} S}\left(\tau_{x z} ; \tau_{y z}\right)\end{array}$ \\
\hline $3[9]$ & $\begin{array}{l}\mathrm{E}_{1} / \mathrm{E}_{2}=15, \mathrm{E}_{2}=10 \mathrm{GPa} \\
\mathrm{G}_{12} / \mathrm{E}_{2}=0.3356 \\
v_{12}=0.3 \\
\alpha_{1} / \alpha_{0}=0.015 \\
\alpha_{2} / \alpha_{0}=1.0\end{array}$ & $\begin{array}{l}(\bar{u}, \bar{v}, \bar{w})=\frac{(u, v, w)}{\alpha_{0} T_{0} h}, \\
\left(\bar{\sigma}_{i}, \bar{\tau}_{i j}\right)=\frac{\left(\sigma_{i}, \tau_{i j}\right)}{\alpha_{0} T_{0} E_{0}} . \\
\alpha_{0}=10^{-6} / K, E_{0}=1 \mathrm{GPa}\end{array}$ \\
\hline
\end{tabular}




\begin{tabular}{|c|c|c|}
\hline $4[6]$ & $\begin{array}{l}\mathrm{E}_{1} / \mathrm{E}_{2}=25, \mathrm{E}_{2}=10 \mathrm{GPa} \\
\mathrm{G}_{12} / \mathrm{E}_{2}=0.5, \mathrm{G}_{13} / \mathrm{E}_{2}=0.5 \\
\mathrm{G}_{23} / \mathrm{E}_{2}=0.2, \\
\mathrm{v}_{12}=\mathrm{v}_{13}=\mathrm{v}_{23}=0.25 \\
\alpha_{2} / \alpha_{1}=1125 . \alpha_{1}=0.015 \times 10^{-6} \mathrm{~K}^{-1}\end{array}$ & $\begin{array}{l}\bar{w}=\frac{w}{h \alpha_{1} T_{0} S^{2}}, \\
(\bar{u}, \bar{v})=\frac{(u, v)}{h \alpha_{1} T_{0} S} \\
\left(\bar{\sigma}_{i}, \bar{\tau}_{i j}\right)=\frac{\left(\sigma_{i}, \tau_{i j}\right)}{E_{2} \alpha_{1} T_{0}} .\end{array}$ \\
\hline $5,6,7[10]$ & $\begin{array}{l}\mathrm{E}_{1}=181 \mathrm{GPa}, \mathrm{E}_{2}=10.3 \mathrm{GPa}, \\
\mathrm{G}_{12}=\mathrm{G}_{13}=7.17 \mathrm{GPa}, \mathrm{G}_{23}=2.87 \mathrm{GPa}, \\
\mathrm{v}_{12}=0.28 \\
\alpha_{1}=0.01 \times 10^{-6} \mathrm{~K}^{-1} \\
\alpha_{2}=22.5 \times 10^{-6} \mathrm{~K}^{-1}\end{array}$ & $\begin{array}{l}(\bar{u}, \bar{v}, \bar{w})=\frac{100(u, v, w / S)}{\alpha_{2} S h T_{0}}, \\
\left(\bar{\sigma}_{x} ; \bar{\sigma}_{y}\right)=\frac{\left(\sigma_{x} ; \sigma_{x}\right)}{\alpha_{2} T_{0} E_{2}} \\
\left(\bar{\tau}_{x z}, \bar{\tau}_{y z}\right)=\frac{1}{E_{2} \alpha_{2} T_{0}}\left(\tau_{x z} ; \tau_{y z}\right) S\end{array}$ \\
\hline
\end{tabular}

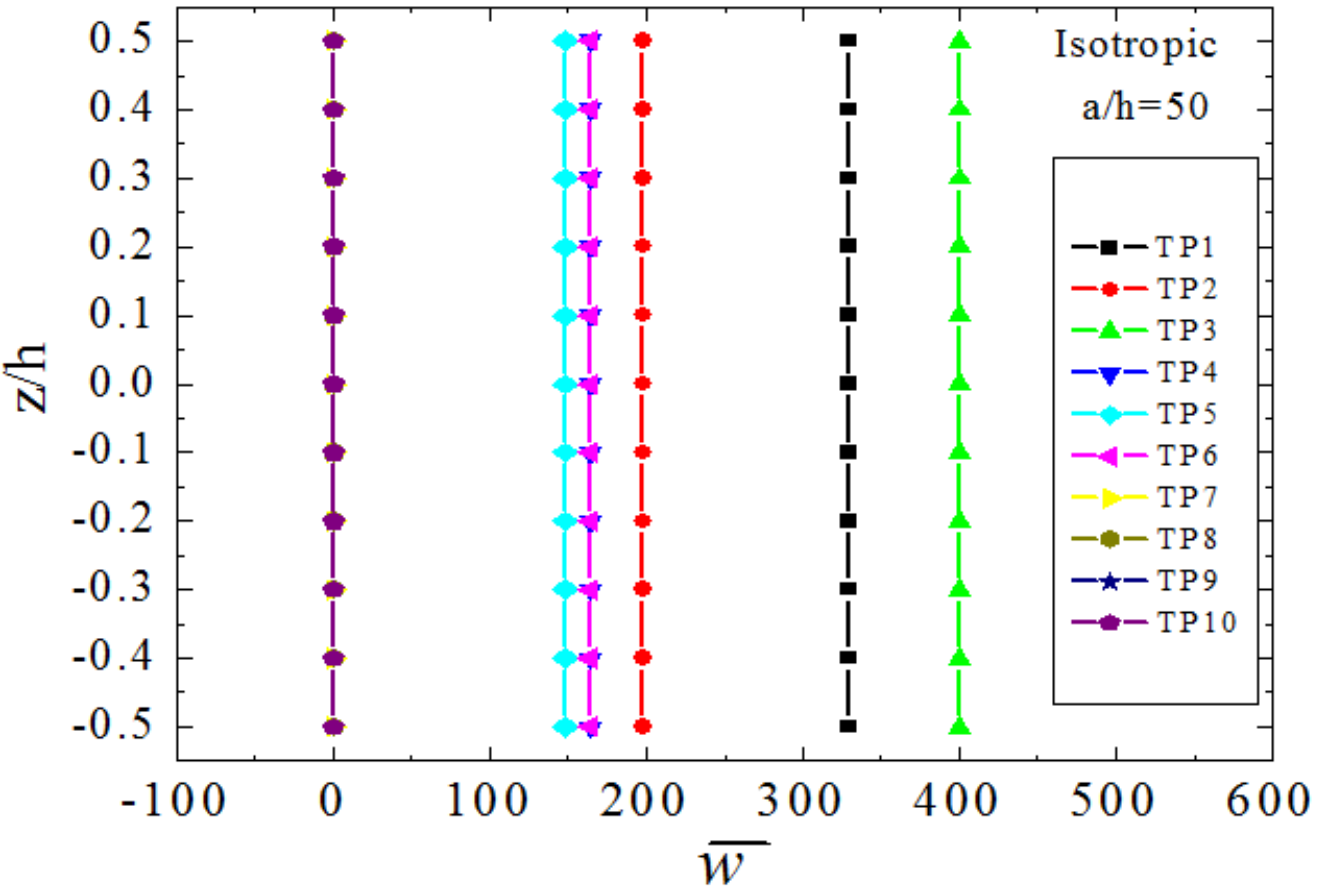

Fig. 3 Normalized transverse displacements $\bar{w}$ through the thickness of an isotropic square plate under thermal loading profiles 1 to 10 for $\mathrm{a} / \mathrm{h}=50$

Fig. 3 shows variation of normalized variation of transverse displacement $(\bar{w})$ across the thickness of the laminate for aspect ratio $(\mathrm{a} / \mathrm{h}=50)$. It is clear from the graph that the transverse displacement $(\bar{w})$ is constant over the thickness for all profiles. Thermal profile 3 having maximum transverse displacement and thermal profiles in Set 3 and Set 4 having zero transverse displacement. Means for symmetric loading from center of plate not shows transverse displacement. Table 3 shows that as aspect ratio increases i.e. for thin plate FOST gives good agreement with $\mathrm{TP}_{1}$ (Gradient load). Results are validated (especially for thin plates) for transverse displacements hence new results prepared for thermal profiles 2 to 10.

Table 3 New results of transverse displacements $\bar{w}:(\mathrm{a} / 2, \mathrm{~b} / 2, \mathrm{~h} / 2)$ for (Set 1 and Set 2$)$ simply supported isotropic square plate subjected to thermal loading.

\begin{tabular}{|c|c|c|c|c|c|c|c|}
\hline $\mathrm{S}=\mathrm{a} / \mathrm{h}$ & Matsunaga[12] & $\mathrm{TP}_{1}$ & $\mathrm{TP}_{2}$ & $\mathrm{TP}_{3}$ & $\mathrm{TP}_{4}$ & $\mathrm{TP}_{5}$ & $\mathrm{TP}_{6}$ \\
\hline 2 & 0.457 & 0.527 & 0.316 & 0.641 & 0.263 & 0.237 & 0.263 \\
& & {$[15.21]$} & & & & & \\
\hline 5 & 3.227 & 3.293 & 1.976 & 4.004 & 1.647 & 1.482 & 1.647 \\
& & {$[2.042]$} & & & & & \\
\hline 10 & 13.110 & 13.172 & 7.903 & 16.015 & 6.586 & 5.927 & 6.586 \\
& & {$[0.47]$} & & & & \\
\hline
\end{tabular}


Study on Transverse Displacement in Composite Laminated Plates across Thickness Subjected ....

\begin{tabular}{|c|c|c|c|c|c|c|c|}
\hline 20 & 52.620 & $\begin{array}{l}52.687 \\
{[0.127]}\end{array}$ & 31.612 & 64.060 & 26.344 & 23.709 & 26.346 \\
\hline 50 & ---- & 329.294 & 197.576 & 400.373 & 164.647 & 148.182 & 164.647 \\
& & & & & & \\
\hline 100 & 1317 & $\begin{array}{l}1317.18 \\
{[0.015]}\end{array}$ & 790.305 & 1601.50 & 658.588 & 592.729 & 658.588 \\
\hline
\end{tabular}

$\mathrm{S}=\mathrm{a} / \mathrm{h}-$ Aspect Ratio, \% Error in $\bar{w}=\left\{\left(\mathrm{TP}_{1}-\right.\right.$ Matsunaga $\left.^{[12]}\right) /$ Matsunaga $\left.^{[12]}\right\} \times 100$

\section{Example 2}

A discussion on the numerical study of single layer $0^{0}$ orthotropic plate under 10 thermal loading using First Order Shear Deformation Theory (FOST) is presented. Results are compared with Kant et $\mathrm{al}^{[11]}$ with gradient thermal profile1. As a part of presentation, \% error in transverse displacement $(\bar{w})$ with $\mathrm{TP}_{1}$ is represented in Table 4. Fig. 4 shows variation of normalized variation of transverse displacement $(\bar{w})$ across the thickness of the laminate for aspect ratio $(\mathrm{a} / \mathrm{h}=50)$. It is clear from the graph that the transverse displacement $(\bar{w})$ is constant over the thickness for all profiles. Thermal profile 3 having maximum transverse displacement and thermal profiles in Set 3 and Set 4 having zero transverse displacement. Table 4 shows that as aspect ratio increases i.e. for thin plate FOST gives good agreement with $\mathrm{TP}_{1}$ (Gradient load). Results are validated (especially for thin plates) for transverse displacements hence new results prepared for thermal profiles 2 to 10 .

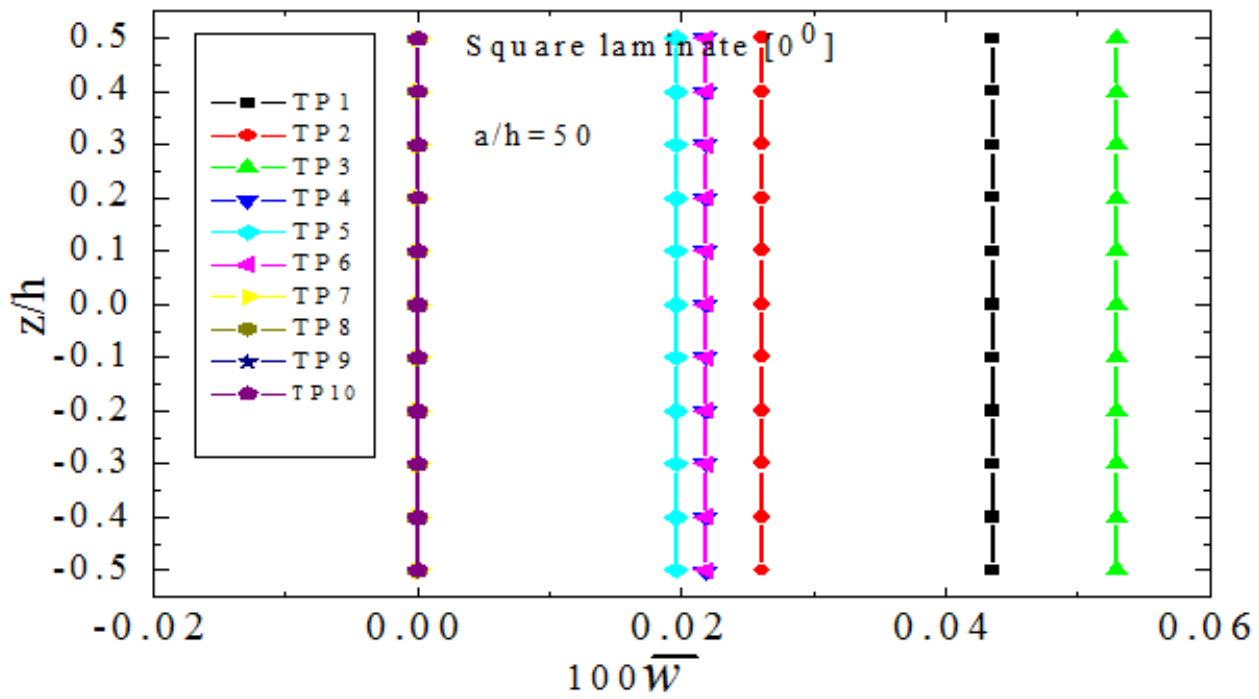

Fig. 4 Normalized transverse displacement $100 \bar{w}$ through the thickness of single layered orthotropic $\left[0^{0}\right]$ square laminate under thermal loading profiles 1 to 10 (all Sets) for $\mathrm{a} / \mathrm{h}=50$

Table 4 New results of transverse displacements $\bar{w}:(a / 2, b / 2, h / 2)$, for simply supported single layered orthotropic $\left[0^{0}\right]$ square laminate subjected to (Set 1$)$ and (Set 2$)$ thermal loading.

\begin{tabular}{|c|c|c|c|c|c|c|c|}
\hline $\mathrm{S}=\mathrm{a} / \mathrm{h}$ & Kant et al $^{[11]}$ & $\mathrm{TP}_{1}$ & $\mathrm{TP}_{2}$ & $\mathrm{TP}_{3}$ & $\mathrm{TP}_{4}$ & $\mathrm{TP}_{5}$ & $\mathrm{TP}_{6}$ \\
\hline 2 & --------- & 0.613 & 0.368 & 0.745 & 0.307 & 0.276 & 0.307 \\
& & & & & & & \\
\hline 4 & 0.090 & $0.104[15.7]$ & 0.063 & 0.127 & 0.052 & 0.047 & 0.052 \\
\hline 5 & -------- & 0.060 & 0.036 & 0.073 & 0.030 & 0.027 & 0.030 \\
\hline 10 & 0.014 & 0.012 & 0.007 & 0.015 & 0.006 & 0.005 & 0.006 \\
& & {$[-14.4]$} & & & & & \\
\hline 20 & 0.003 & 0.003 & 0.0017 & 0.0034 & 0.0014 & 0.0013 & 0.0014 \\
& & {$[-4.42]$} & & & & & 0.0002 \\
\hline 50 & ---------- & 0.0004 & 0.0003 & 0.0005 & 0.0002 & 0.0002 & 0.0001 \\
\hline 100 & ------- & 0.0001 & 0.0001 & 0.0001 & 0.0001 & 0.0001 & 0.0001 \\
\hline
\end{tabular}

$\mathrm{S}=\mathrm{a} / \mathrm{h}-$ Aspect Ratio, $\left[\mathrm{]} \%\right.$ Error $=\left\{\left(\mathrm{TP}_{1}-\right.\right.$ Kant et al $\left.^{-[1]}\right) /$ Kant et al. $\left.{ }^{[11]}\right\} \times 100$.

\section{Example 3}

A simply supported square unsymmetric $\left(0^{\circ} / 90^{\circ}\right)$ laminate under bi-directional bending subjected to gradient thermal loading $\left(\mathrm{TP}_{1}\right)$ as well as thermal profiles 2 to 10 is analysed and results are compared with 3D 
elasticity solution ${ }^{[3]}$. Fig. 5 shows variation of normalized variation of transverse displacement $(\bar{w})$ across the thickness of the laminate for aspect ratio 50. It is clear from the graph that the transverse displacement $(\bar{w})$ is constant over the thickness. Table 5 shows that as aspect ratio increases i.e. for thin plate FOST gives good agreement with $\mathrm{TP}_{1}$ (Gradient load). Results are validated (especially for thin plates) for transverse displacements hence new results prepared for thermal profiles 2 to 10 .

Table 5 New results of transverse displacements $\bar{w}:(a / 2, b / 2,0)$, for simply supported unsymmetrical 2 layered $\left[0^{0} / 90^{0}\right]$ square laminated plate subjected to (Set 1 to Set 4 ) thermal loading

\begin{tabular}{|c|c|c|c|c|c|c|c|c|c|c|c|}
\hline $\mathrm{S}=\mathrm{a} / \mathrm{h}$ & Pagano $^{[3]}$ & $\mathrm{TP}_{1}$ & $\mathrm{TP}_{2}$ & $\mathrm{TP}_{3}$ & $\mathrm{TP}_{4}$ & $\mathrm{TP}_{5}$ & $\mathrm{TP}_{6}$ & $\mathrm{TP}_{7}$ & $\mathrm{TP}_{8}$ & $\mathrm{TP}_{9}$ & $\mathrm{TP}_{10}$ \\
\hline 2 & ----- & 0.166 & 0.09 & 0.204 & 5.075 & 2.754 & 3.533 & 9.984 & 3.817 & 5.481 & 6.167 \\
\hline 4 & ---- & 0.666 & 0.39 & 0.816 & 5.325 & 2.977 & 3.783 & 9.984 & 3.817 & 5.481 & 6.167 \\
\hline 5 & 0.997 & $\begin{array}{l}1.040 \\
{[4.3]}\end{array}$ & 0.61 & 1.275 & 5.512 & 3.145 & 3.970 & 9.984 & 3.817 & 5.481 & 6.167 \\
\hline 10 & 4.120 & $\begin{array}{l}4.160 \\
{[0.97]}\end{array}$ & 2.42 & 5.100 & 7.072 & 4.542 & 5.530 & 9.984 & 3.817 & 5.481 & 6.167 \\
\hline 20 & 16.60 & $\begin{array}{l}16.64 \\
{[0.25]}\end{array}$ & 9.69 & 20.40 & 13.31 & 10.13 & 11.77 & 9.984 & 3.817 & 5.481 & 6.167 \\
\hline 50 & ------ & 104 & 60.6 & 127.5 & 56.99 & 49.25 & 55.45 & 9.984 & 3.817 & 5.481 & 6.167 \\
\hline 100 & ---- & 416 & 242 & 510 & 213 & 188.9 & 211.5 & 9.984 & 3.817 & 5.481 & 6.167 \\
\hline
\end{tabular}

$\mathrm{S}=\mathrm{a} / \mathrm{h}-$ Aspect Ratio, []$\%$ Error $=\left\{\left(\mathrm{TP}_{1}-\right.\right.$ Pagano $\left.^{[3]}\right) /$ Pagano $\left.\left.^{[3]}\right\}\right) \times 100$

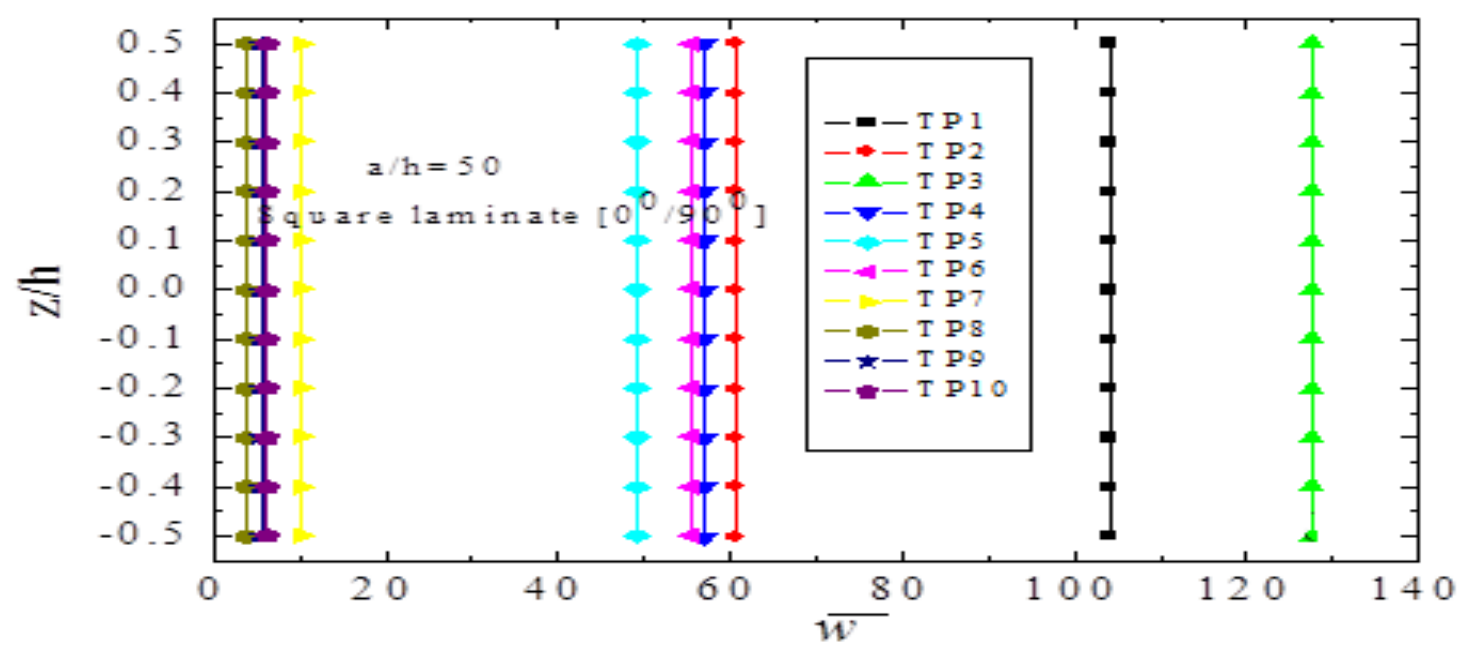

Fig. 5 Normalized transverse displacement $\bar{w}$ through the thickness of an unsymmetrical 2 layered $\left[0^{0} / 90^{0}\right]$ square laminate under thermal loading profiles 1 to 10 (Set1 to Set 4) for $a / h=50$

\section{Example 4}

A simply supported square cross-ply symmetric $\left(0^{\circ} / 90^{\circ} / 0^{\circ}\right)$ laminated plate under bi-directional bending subjected to linear thermal profile as well as thermal profiles 2 to 10 is analysed. Normalized results for transverse displacements $(\bar{w})$ are tabulated in Table 6 for different aspect ratios. Results are compared with 3D elasticity solution given in ${ }^{[6]}$ for very thick $(\mathrm{a} / \mathrm{h}=2)$ to thin $(\mathrm{a} / \mathrm{h}=100)$ laminates and are in good agreement with elasticity solution. Table 6 shows that as aspect ratio increases i.e. for thin plate FOST gives good agreement with $\mathrm{TP}_{1}$ (Gradient load). Results are validated (especially for thin plates) for transverse displacements hence new results prepared for thermal profiles 2 to 10 . Variations of the transverse displacements over the thickness of the laminates are expressed in the Fig. 6 for aspect ratio 50. It is clear from the graph that the transverse displacement $(\bar{w})$ is constant over the thickness.

Table 6 New results of normalized transverse displacements $\bar{w}:(a / 2, b / 2, \mathrm{~h} / 2)$, for simply supported symmetrical 3 layered $\left[0^{\circ} / 90^{\circ} / 0^{\circ}\right]$ laminated square plate subjected to (Set 1$)$ and (Set 2$)$ thermal loading

\begin{tabular}{|c|c|c|c|c|c|c|c|}
\hline $\mathrm{S}=\mathrm{a} / \mathrm{h}$ & Bhaskar $^{[6]}$ & $\mathrm{TP}_{1}$ & $\mathrm{TP}_{2}$ & $\mathrm{TP}_{3}$ & $\mathrm{TP}_{4}$ & $\mathrm{TP}_{5}$ & $\mathrm{TP}_{6}$ \\
\hline 2 & 96.79 & 31.230 & 19.101 & 37.759 & 15.615 & 14.099 & 15.615 \\
& & {$[-67.7]$} & & & & & \\
\hline 4 & 42.69 & 21.448 & 13.064 & 25.964 & 10.724 & 9.676 & 10.724 \\
& & {$[-49.8]$} & & & & & \\
\hline 5 & ------- & 18.536 & 11.266 & 22.453 & 9.268 & 8.359 & 9.268 \\
\hline 10 & 17.39 & 12.83 & 7.744 & 15.572 & 6.415 & 5.779 & 6.415 \\
& & {$[-26.2]$} & & & & & \\
\hline
\end{tabular}


Study on Transverse Displacement in Composite Laminated Plates across Thickness Subjected ....

\begin{tabular}{|c|c|c|c|c|c|c|c|}
\hline 20 & 12.12 & $\begin{array}{l}10.890 \\
{[-10.1]}\end{array}$ & 6.546 & 13.234 & 5.445 & 4.9021 & 5.445 \\
\hline 50 & 10.50 & $\begin{array}{l}10.296 \\
{[-1.94]}\end{array}$ & 6.18 & 12.517 & 5.148 & 4.633 & 5.148 \\
\hline 100 & 10.26 & $\begin{array}{l}10.209 \\
{[-0.49]}\end{array}$ & 6.126 & 12.413 & 5.105 & 4.594 & 5.105 \\
\hline
\end{tabular}

$\mathrm{S}=\mathrm{a} / \mathrm{h}-$ Aspect Ratio, [] \% Error $=\left\{\left(\mathrm{TP}_{1}-\right.\right.$ Bhaskar $\left.^{[0]}\right) /$ Bhaskar $\left.^{[6]}\right\} \times 100$

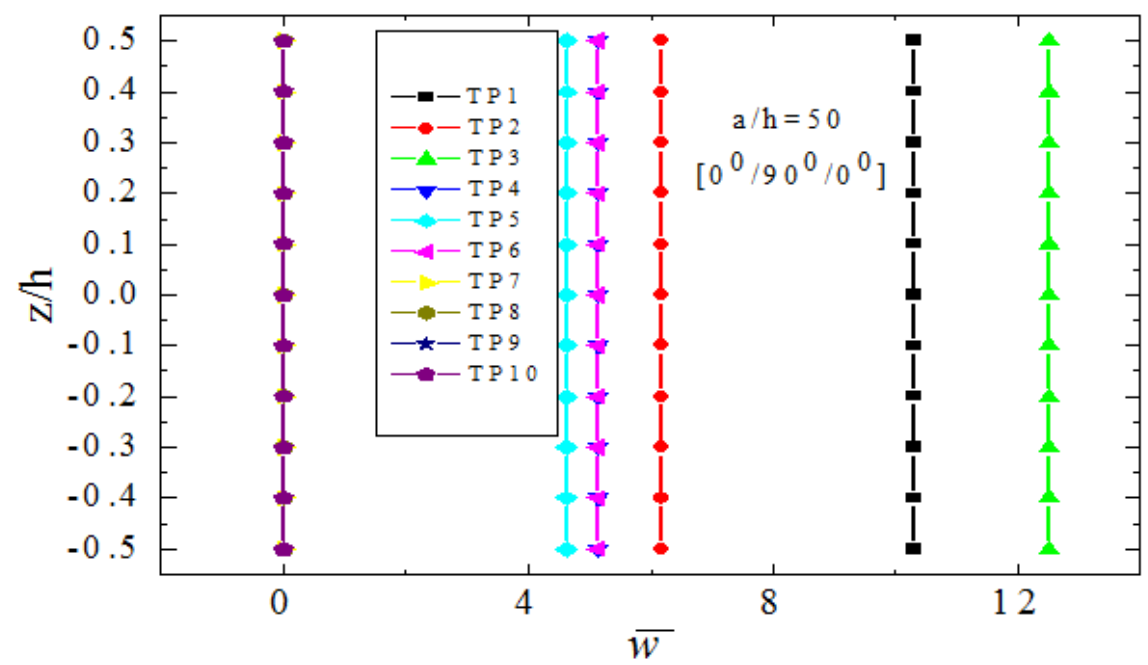

Fig. 6 Normalized transverse displacements $\bar{w}$ through the thickness of simply supported symmetrical 3 layered $\left[0^{\circ} / 90^{\circ} / 0^{\circ}\right]$ laminated square plate under thermal loading profiles 1 to 10 (Set1 to Set 4 ) for $a / h=50$

\section{Example 5}

A simply supported square symmetric $\left(0^{\circ} / 90^{\circ} / 90^{\circ} / 0^{\circ}\right)$ laminated plate under bi-directional bending subjected to linear thermal profile as well as thermal profiles 2 to 10 is analyzed using FOST. Normalized results for transverse displacements $(\bar{w})$ are tabulated in Table 7 for different aspect ratios. Results are compared with solution given in $^{[10]}$ for very thick $(\mathrm{a} / \mathrm{h}=2)$ to thin $(\mathrm{a} / \mathrm{h}=100)$ laminates and are in good agreement with solution especially for $\mathrm{TP}_{1}$. In case of transverse displacement $\bar{w}$, error varies from $-43.40 \%$ for aspect ratio 5 and as a/h ratio increases, error decreases which becomes $-7.03 \%$ for aspect ratio 20 at top of plate. Results are validated (especially for thin plates) for transverse displacements hence new results are prepared for thermal profiles 2 to 10 . Variations of the transverse displacements over the thickness of the laminates are expressed in the Fig. 7 for aspect ratio 50. It is clear from the graph that the transverse displacement $(\bar{w})$ is constant over the thickness.

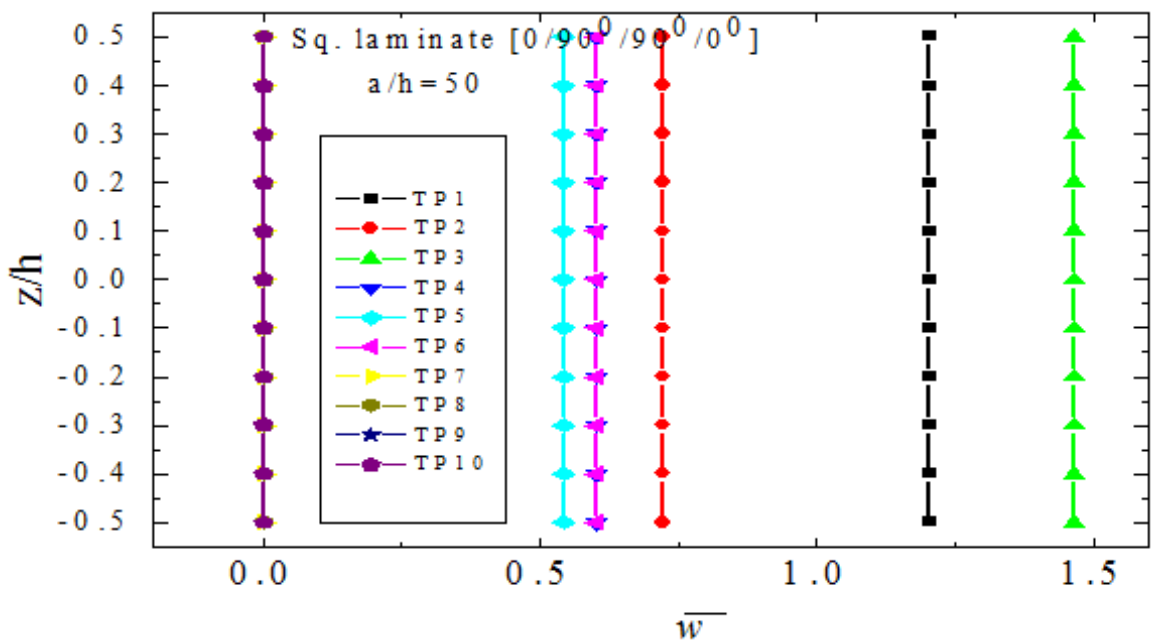

Fig. 7 Normalized transverse displacements $\bar{w}$ through the thickness four layered symmetrical $\left[0^{\circ} / 90^{\circ} / 90^{\circ} / 0^{\circ}\right]$ laminated square plate simply supported on all edges under thermal loading profiles 1 to 10 (Set1 to Set 4) for $a / h=50$ 
Study on Transverse Displacement in Composite Laminated Plates across Thickness Subjected ....

Table 7 New results of transverse displacements $\bar{w}:(a / 2, b / 2, \mathrm{~h} / 2)$, for simply supported symmetrical 4 layered $\left[0^{\circ} / 90^{\circ} / 90^{\circ} / 0^{\circ}\right]$ laminated square plate subjected to (Set 1$)$ and (Set 2$)$ and (Set 3$)$ thermal loading

\begin{tabular}{|c|c|c|c|c|c|c|c|c|}
\hline $\mathrm{S}=\mathrm{a} / \mathrm{h}$ & Kapuria & $\mathrm{TP}_{1}$ & $\mathrm{TP}_{2}$ & $\mathrm{TP}_{3}$ & $\mathrm{TP}_{4}$ & $\mathrm{TP}_{5}$ & $\mathrm{TP}_{6}$ & $\mathrm{TP}_{7}$ \\
\hline 2 & ------- & 2.126 & 1.334 & 2.551 & 1.063 & 0.964 & 1.063 & 1.063 \\
\hline 4 & ------- & 1.686 & 1.042 & 2.032 & 0.843 & 0.763 & 0.843 & 0.843 \\
\hline 5 & 2.753 & $\begin{array}{c}1.558 \\
{[-43.40]}\end{array}$ & 0.957 & 1.881 & 0.779 & 0.704 & 0.779 & 0.779 \\
\hline 10 & 1.645 & $\begin{array}{c}1.312 \\
{[-20.26]}\end{array}$ & 0.794 & 1.591 & 0.656 & 0.591 & 0.656 & 0.656 \\
\hline 20 & 1.316 & $\begin{array}{c}1.229 \\
{[-7.03]}\end{array}$ & 0.739 & 1.4931 & 0.615 & 0.553 & 0.615 & 0.615 \\
\hline 50 & & 1.204 & 0.723 & 1.463 & 0.602 & 0.542 & 0.602 & 0.602 \\
\hline 100 & --------- & 1.200 & 0.720 & 1.459 & 0.600 & 0.540 & 0.600 & 0.600 \\
\hline
\end{tabular}

$\mathrm{S}=\mathrm{a} / \mathrm{h}-$ Aspect Ratio, $\left[\right.$ ] \% Error $=\left\{\left(\mathrm{TP}_{1}-\right.\right.$ Kapuria $\left.^{[10]}\right) /$ Kapuria $\left.^{[10]}\right\} \times 100$

\section{Example 6}

A simply supported rectangular $(\mathrm{b} / \mathrm{a}=2)$ symmetric $\left(0^{0} / 90^{\circ} / 90^{\circ} / 0^{0}\right)$ laminated plate under bi-directional bending subjected to linear thermal profile as well as thermal profiles 2 to 10 is analysed using FOST. Normalized results for transverse displacements $(\bar{w})$ are tabulated in Table 8 for different aspect ratios. Results are compared with solution given $\operatorname{in}^{[10]}$ for very thick $(\mathrm{a} / \mathrm{h}=2)$ to thin $(\mathrm{a} / \mathrm{h}=100)$ laminates and are in good agreement with solution especially for $\mathrm{TP}_{1}$. In case of transverse displacement $\bar{w}$, error varies from $-52 \%$ for aspect ratio 5 and as a/h ratio increases, error decreases which becomes $-8.26 \%$ for aspect ratio 20 at top of plate. Results are validated (especially for thin plates) for transverse displacements hence new results are prepared for thermal profiles 2 to 10. Set 3 and Set 4 having zero transverse displacement. Variations of the transverse displacements over the thickness of the laminates are expressed in the Fig. 8 for aspect ratio 50. It is clear from the graph that the transverse displacement $(\bar{w})$ is constant over the thickness.

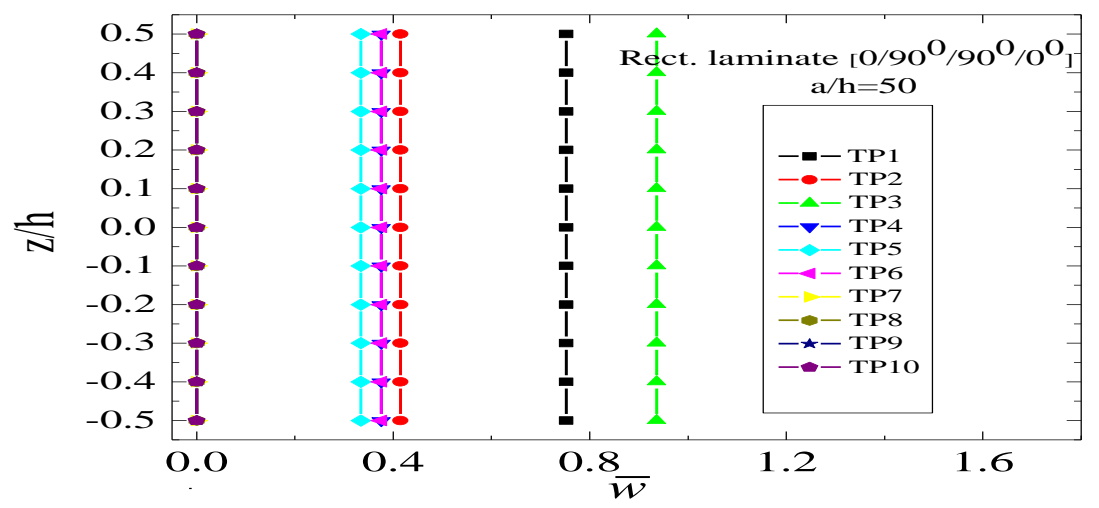

Fig. 8 Normalized transverse displacements $\bar{w}$ through the thickness symmetrical 4 layered $\left[0^{0} / 90^{0} / 90^{\circ} / 0^{0}\right]$ laminated rectangular $(\mathrm{b} / \mathrm{a}=2)$ plate simply supported on all edges under thermal loading profiles 1 to 10 (Set1 to Set 4) for $a / h=50$

Table 8 New results of transverse displacements $\bar{w}:(a / 2, b / 2, \mathrm{~h} / 2)$, for simply supported symmetrical 4 layered $\left[0^{0} / 90^{\circ} / 90^{\circ} / 0^{0}\right]$ laminated rectangular $(\mathrm{b} / \mathrm{a}=2)$ plate subjected to (Set 1$)$ and $($ Set 2$)$ thermal loading

\begin{tabular}{|c|c|c|c|c|c|c|c|}
\hline $\mathrm{S}=\mathrm{a} / \mathrm{h}$ & Kapuria $^{[10]}$ & $\mathrm{TP}_{1}$ & $\mathrm{TP}_{2}$ & $\mathrm{TP}_{3}$ & $\mathrm{TP}_{4}$ & $\mathrm{TP}_{5}$ & $\mathrm{TP}_{6}$ \\
\hline 2 & ---------- & 1.584 & 0.959 & 1.921 & 0.792 & 0.714 & 0.792 \\
\hline 4 & -------- & 1.055 & 0.613 & 1.294 & 0.527 & 0.472 & 0.527 \\
\hline 5 & 1.995 & $\begin{array}{c}0.957 \\
{[-52]}\end{array}$ & 0.549 & 1.178 & 0.478 & 0.427 & 0.478 \\
& & $\begin{array}{c}0.806 \\
{[-25.22]}\end{array}$ & 0.450 & 0.999 & 0.403 & 0.359 & 0.403 \\
\hline 10 & 1.078 & 0.764 & 0.423 & 0.950 & 0.382 & 0.340 & 0.382 \\
& & {$[-8.26]$} & & & & & \\
\hline 20 & 0.833 & 0.754 & 0.416 & 0.937 & 0.377 & 0.335 & 0.377 \\
\hline 50 & ---------- & 0.7524 & 0.415 & 0.936 & 0.376 & 0.334 & 0.376 \\
\hline 100 & ----------- & 0.751 & 0.414 & 0.934 & 0.375 & 0.333 & 0.375 \\
\hline
\end{tabular}

$\mathrm{S}=\mathrm{a} / \mathrm{h}-$ Aspect Ratio, []$\%$ Error $=\left\{\left(\mathrm{TP}_{1}-\right.\right.$ Kapuria $\left.^{[10]}\right) /$ Kapuria $\left.^{[10]}\right\} \times 100$ 


\section{Example 7}

A simply supported square $(\mathrm{b} / \mathrm{a}=1)$ unsymmetric $\left(90^{\circ} / 0^{\circ} / 90^{\circ} / 0^{\circ}\right)$ laminated plate under bi-directional bending subjected to thermal gradient $\mathrm{TP}_{1}$ as well as thermal profiles 2 to 10 is presented using FOST.

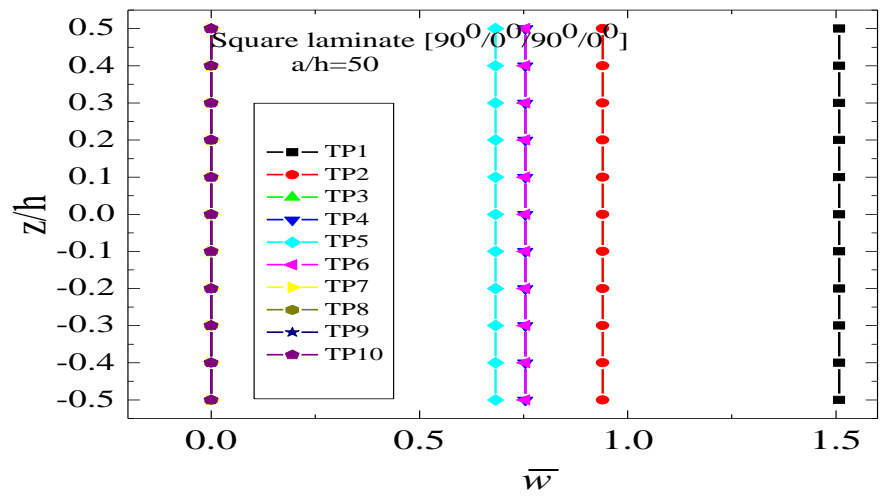

Fig. 9 Normalized transverse displacements $\bar{w}$ through the thickness unsymmetrical 4 layered $\left[90^{0} / 0^{0} / 90^{\circ} / 0^{0}\right]$ laminated square plate simply supported on all edges under thermal loading profiles 1 to 10 (Set1 to Set 4) for

$$
a / h=50
$$

Normalized results for transverse displacements $(\bar{w})$ are tabulated in Table 9 for different aspect ratios. Results are compared with solution given in ${ }^{[10]}$ for very thick $(\mathrm{a} / \mathrm{h}=2)$ to thin $(\mathrm{a} / \mathrm{h}=100)$ laminates and are in good agreement with solution especially for $\mathrm{TP}_{1}$. In case of transverse displacement $\bar{w}$, error varies from $-45.88 \%$ for aspect ratio 5 and as a/h ratio increases, error decreases which becomes $-5.371 \%$ for aspect ratio 20 at top of plate. Results are validated (especially for thin plates) for transverse displacements hence new results are prepared for thermal profiles 2 to 10 . Set 3 and Set 4 having zero transverse displacement. Variations of the transverse displacements over the thickness of the laminates are expressed in the Fig. 9 for aspect ratio 50 . It is clear from the graph that the transverse displacement $(\bar{w})$ is constant over the thickness.

Table 9 New results of transverse displacements $\bar{w}:(a / 2, b / 2, \mathrm{~h} / 2)$, for simply supported unsymmetrical 4 layered $\left[90^{\circ} / 0^{\circ} / 90^{\circ} / 0^{\circ}\right]$ laminated square plate subjected to (Set 1) and (Set 2) thermal loading

\begin{tabular}{|c|c|c|c|c|c|c|c|}
\hline$S=a / h$ & Kapuria $^{[10]}$ & $\mathrm{TP}_{1}$ & $\mathrm{TP}_{2}$ & $\mathrm{TP}_{3}$ & $\mathrm{TP}_{4}$ & $\mathrm{TP}_{5}$ & $\mathrm{TP}_{6}$ \\
\hline 2 & ----------- & 1.508 & 0.940 & 1.813 & 0.754 & 0.683 & 0.754 \\
\hline 4 & ----------- & 1.508 & 0.940 & 1.813 & 0.754 & 0.683 & 0.754 \\
\hline 5 & 2.789 & $\begin{array}{c}1.508 \\
{[-45.88]}\end{array}$ & 0.940 & 1.813 & 0.754 & 0.683 & 0.754 \\
\hline 10 & 1.846 & $\begin{array}{c}1.508 \\
{[-18.24]}\end{array}$ & 0.940 & 1.813 & 0.754 & 0.683 & 0.754 \\
\hline 20 & 1.594 & $\begin{array}{c}1.508 \\
{[-5.371]}\end{array}$ & 0.940 & 1.813 & 0.754 & 0.683 & 0.754 \\
\hline 40 & ----------- & 1.508 & 0.940 & 1.813 & 0.754 & 0.683 & 0.754 \\
\hline 50 & ----------- & 1.508 & 0.940 & 1.813 & 0.754 & 0.683 & 0.754 \\
\hline 100 & ----------- & 1.508 & 0.940 & 1.813 & 0.7541 & 0.683 & 0.754 \\
\hline
\end{tabular}

\section{Conclusion}

First Order Shear Deformation Theory (FOST) is presented for thermal stress analysis of isotropic plate and composite laminates. Present theory accounts for thermal expansion coefficient in the transverse normal direction. Thermal loading with ten different orientations are considered along thickness direction is considered over the cross-ply laminates. The present FOST is assessed by comparison with the 3D exact and other 2D models. FOST provide good results only in case of very thin laminates with aspect ratio (S) more than 40. It is clear from the comparisons, that the performance of present FOST is good in the estimation of global as well as local quantities of laminates subjected to thermal gradient as well as profile 2 to 10 for almost all aspect ratios.

Following conclusions are drawn based on the results obtained and as discussed above. The pattern of all the results is almost found very parallel for all above considered plates. 
(1) Transverse Displacement $\bar{w}$ remains constant throughout the thickness of plate for given aspect ratio in all thermal profiles and all selected plates. For the general idea, the variations in the numeric values of some of the plates are given in following conclusions.

(2) In Set $1\left(\mathrm{TP}_{1}, \mathrm{TP}_{2}, \mathrm{TP}_{3}\right)$ the variation of $\mathrm{TP}_{3}$ is more than $\mathrm{TP}_{1}$ and $\mathrm{TP}_{2}$ by about $18.875 \%$ and $85.75 \%$ respectively and hence for example it reflects in transverse displacement $\bar{w}$ which gives maximum value of 64.0597 and 0.0034 for isotopic and single layer $0^{0}$ orthotropic plate respectively to aspect ratio 20 for $\mathrm{TP}_{3}$. This trend is seen in all thermal profiles and all selected plates.

(3) In Set $2\left(\mathrm{TP}_{4}, \mathrm{TP}_{5}, \mathrm{TP}_{6}\right)$, the variation in $\mathrm{TP}_{4}$ and $\mathrm{TP}_{6}$ ordinates are symmetric from mid plane therefore $\bar{w}$ is same and maximum i. e. $26.3435,0.0014$ etc. for isotropic , single layer $0^{0}$ orthotropic plate etc. respectively for given aspect ratio 20 . It is seen in all aspect ratios, thermal profiles and all selected plates except two layer $0^{\circ} / 90^{\circ}$ unsymmetrical plate because due to asymmetry.

(4) Zero transverse displacement $\bar{w}$ for Set $3\left(\mathrm{TP}_{7}, \mathrm{TP}_{8}, \mathrm{TP}_{9}\right)$ and Set $4\left(\mathrm{TP}_{10}\right)$, profiles as thermal loads are symmetric on the mid plane of the plate for given aspect ratio in all thermal profiles and all selected plates.

\section{References}

[1]. E. Reissner, The Effect of Transverse Shear Deformation on the Bending of Elastic Plates, ASME J. Applied Mechanics, vol. 12, pp. 69-77, 1945

[2]. R. D. Mindlin, Influence of Rotatory Inertia and Shear Deformation on Flexural Motions of Isotropic Elastic Plates, ASME J. Applied Mechanics, vol. 18, pp. 31-38, 1951.

[3]. N. J Pagano, Exact Solution for Composite Laminated in Cylindrical Bending, Journal of Composite Materials, vol. 3, pp. 398-411, 1969.

[4]. T. Kant and R. K. Khare, Finite Element Thermal Stress Analysis of Composite Laminates Using A Higher-order Theory, $J$. Thermal Stresses, vol. 17, pp. 229-255, 1994.

[5]. V. B. Tungikar and K. M. Rao, Three-Dimensional Exact Solution of Thermal Stresses in Rectangular Composite Laminate, Composite Structures, vol. 27, pp. 419-430, 1994.

[6]. K. Bhaskar, T. K. Varadan, and J. S. M. Ali, Thermoelastic Solutions for Orthotropic and Anisotropic Composite Laminates, Composites: Part B, vol. 27B, pp. 415-420, 1996.

[7]. K. Rohwer, R. Rolfes, and H. Sparr, Higher-order Theories for Thermal Stresses in Layered Plates, Int. J. Solids and Structures, vol. 38, pp. 3673-3687, 2001.

[8]. T. Kant and K. Swaminathan, Analytical Solutions for Static Analysis of Laminated Composite and Sandwich Plates Based on a Higher Order Refined Theory, Composite Structures, vol. 56, pp. 329-344, 2002.

[9]. H. Matsunaga, A Comparison Between 2-D Single-Layer and 3-D Layerwise Theories for Computing Interlaminar Stresses of Laminated Composite and Sandwich Plates Subjected to Thermal Loadings, Composite Structures, vol. 64, pp. 161-177, 2004.

[10]. S. Kapuria and G. G. S. Achary, An Efficient Higher Order Zigzag Theory for Laminated Plates Subjected to Thermal Loading, International Journal of Solids and Structures, vol. 41(16-17), pp. 4661-4684, 2004.

[11]. T. Kant, Y. Desai, and S. Pendhari, An Efficient Semi-Analytical Model for Composite and Sandwich Plate Subjected to Thermal Load, Journal of Thermal Stresses, vol. 31, pp. 77-103, 2008.

[12]. H. Matsunaga, Stress analysis of functionally graded plates, subjected plates subjected to thermal and mechanical loadings, Composite Structures, vol. 87, pp. 344-377, 2009.

[13]. T.Kant, S. M. Shiyekar, An assessment of a higher order theory for composite laminates subjected to thermal gradient, Composite Structures, vol. 96, pp. 698-707, 2013. 